\title{
Walled-off nekroz tedavisinde endoskopik nekrozektomi: Olgu sunumu
}

\author{
Endoscopic necrosectomy in the treatment of wall-off necrosis: A case report
}

Muhammet Yener AKPINAR ${ }^{1}$, Bülent ÖDEMIŞ' ${ }^{1}$ Erkin ÖZTAŞ ${ }^{1}$, Orhan ÇOŞKUN ${ }^{1}$, Mustafa KAPLAN ${ }^{1}$

Türkiye Yüksek Ihtisas Eğitim ve Araştırma Hastanesi, Gastroenteroloji Kliniği, Ankara

Walled-off nekroz, nekrotizan pankreatit geçiren hastalarda görülebilen ciddi bir komplikasyondur. Walled-off nekroz klinik olarak asemptomatik olabileceği gibi farklı ateş, bulantı-kusma, karın ağnısı gibi semptomlarla da kendini gösterebilir. Endoskopik nekrozektomi son yıllarda kullanım sıklığı artan bir tedavi yöntemidir. Perkütan drenaja kıyasla başarı şansı yüksektir. Cerrahi nekrozektomiye kıyasla da daha az mortaliteye sahiptir.

Anahtar kelimeler: Endoskopik nekrozektomi, walled-off nekroz

\section{GİRISş}

Akut pankreatitle ilgili tanımlamalar 2012 Atlanta toplantısında revize edilmiştir (1). Son hali ile peripankreatik sıvı koleksiyonları dört ana başlıkta toplanmıştır. Akut peripankreatik sıvı koleksiyonu, akut nekrotik koleksiyon, pankreatik psödokist ve walled-off nekroz (WON). Ciddi akut pankreatit geçiren hastaların yaklaşı \% 15 kadarında oluşan WON asemptomatik olabileceği gibi enfekte olup ateş, karın ağrısı gibi semptomlara ya da kitle etkisiyle komşu organlara yaptığı bası sonucu ortaya çıkan bulgularla kendini gösterebilir (2). Endoskopik tedaviler son ylllarda psödokistlerde olduğu gibi WON'da da uygun hastalarda daha sık kullanılır hale gelmiştir (3). Biz burada endoskopik nekrozektomi yaptığımız bir olguyu sunduk.

\section{OLGU SUNUMU}

Otuz üç yaşında erkek hasta hastanemize karın ağrısı ve yemeklerden sonra olan bulantı şikayetleri ile başvurdu. Özgeçmişinde hipotiroidi ve tip-2 diabetes mellitus (DM) tanıları olan ve 2 ay önce akut pankreatit geçirdiği öğrenilen hastanın şikayetleri giderek artış göstermişti. Laboratuvar tahlillerinde hemoglobin: 14,1 g/dl, lökosit: 4.500x103/uL, alanin aminotransferaz: $24 \mathrm{U} / \mathrm{L}$, aspartat aminotransferaz: $17 \mathrm{U} / \mathrm{L}$, gama glutamil transpeptidaz: $18 \mathrm{U} / \mathrm{L}$, alkalen fosfataz: $98 \mathrm{U} / \mathrm{L}$, total bilirübin: $1,07 \mathrm{mg} / \mathrm{dl}$, direk bilirübin: $0,10 \mathrm{mg} / \mathrm{dl}$, sedimantasyon: $33 \mathrm{~mm} / \mathrm{saat}$ ve C-reaktif protein: $20,5 \mathrm{mg} / \mathrm{dl}$ olarak tespit edildi. Abdomen tomografisinde pankreas gövde ve kuyruk kesiminden köken alıp mide korpusunu basılayan, 79x141 mm boyutlarında yoğun içerikli, WON ile uyumlu kistik lezyon izlendi (Resim 1). Semptomatik olan hastaya endoskopik nekrozektomi planlandı. Bilgisayarlı tomografi (BT) bulguları eşliğinde WON’un mideye en fazla bası yaptığı

Akpınar MY, Ödemiş B, Öztaş E, et al. Endoscopic necrosectomy in the treatment of wall-off necrosis: A case report. Endoscopy Gastrointestinal 2017;25:21-23.
Walled-off necrosis is a serious complication of acute necrotizing pancreatitis. Clinically, walled-off necrosis can be asymptomatic or can lead to various symptoms, including fever, abdominal pain, and nausea. Nowadays, the choice of endoscopic necrosectomy as a treatment option for walled-off is increasing rapidly, in part because it is more effective than percutaneous drainage. Also, the mortality rate is lower in walled-off than in surgical necrosectomy.

Key words: Endoscopic necrosectomy, walled-off necrosis

lokalizasyondan iğne uçlu sfinkterotom ile kist içine girilerek kılavuz tel kist içine bırakıldı. Bu esnada yoğun bir şekilde serohemorajik kist içeriğinin mide lümenine geldiği görüldü. Kılavuz tel üzerinden $8 \mathrm{~mm}$ balon dilatasyonu yapıldıktan sonra 30x16 mm boyutlarında ve her iki ucu çan şeklinde olan pankreatik psödokist stenti (Micro-Tech, Nanjing, Jiangsu, China) yerleştirildi (Resim 2). Stent yerleştirilirken önce WON kavitesi içindeki ucu açıldı ve bir süre beklendikten sonra mide lümeni içindeki diğer ucu açlld. Metal stentin içerisinden ayrıca nazokistik dren yerleştirildi. Nazokistik dren yardımıyla kist içi 2 hafta boyunca 4-6 satte bir 100-200 cc serum fizyolojik ile yıkanan hastaya bir sonraki seansta ön görüşlü endoskopla girildi. Metal stentin içinden WON kavitesine girildi ve kist içinde kalmış nekrotik materyaller taş balonu ve serum fizyolojikle ylkanarak temizlendi (Resim 3,4). Takiplerinde şikayetleri düzelen hastanın kontrol BT'sinde kist çapı 20x16 mm'ye gerilemişti (Resim 5). Metalik stenti çıkarılan hasta önerilerle taburcu edildi.

\section{TARTIŞMA}

Akut pankreatit gerek sistemik, gerekse de lokal komplikasyonlara yol açabilen bir hastalıktır. Oluşan komplikasyonlar hastaların morbidite ve mortalitesinde artışa yol açar. Akut pankreatit seyri esnasında ortaya çıkan peripankreatik sıvı koleksiyonları dört haftadan uzun süre devam ederse olgunlaşıp sınırları belirgin hale gelen kitlelere dönüşür. Interstisyel pankreatit geçiren hastalarda ilk evrelerde oluşabilen akut peripankreatik sıvı koleksiyonları psödokistlere, nekrotizan pankreatit geçiren hastalarda görülen akut nekrotik koleksiyonlar ise WON'a ilerleyebilir (4). AP geçiren hastalarda atak sonrası oluşabilen WON veya pankreatik psödokistler enfek-
İletişim: Muhammet Yener AKPINAR Türkiye Yüksek İhtisas Eğitim ve Araştırma Hastanesi, Gastroenteroloji Kliniği, Kızılay Caddesi, Sıhhiye, 06100, Ankara Tel: +90 31230613 20•Fax: +90 31231241 20•muhammet.yener@gmail.com Geliş Tarihi: 16.02.2017 Kabul Tarihi: 14.04.2017 


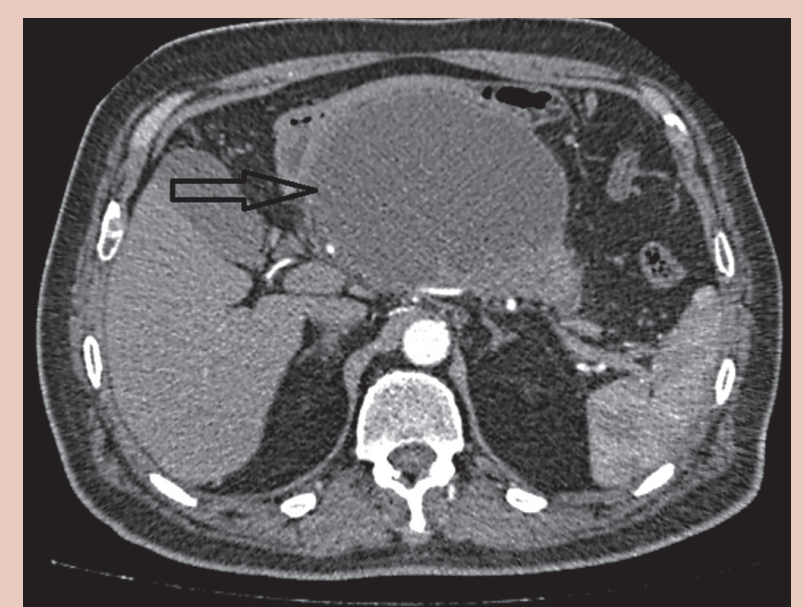

Resim 1. Mideye bası yapan 79x141 mm boyutlarında WON.

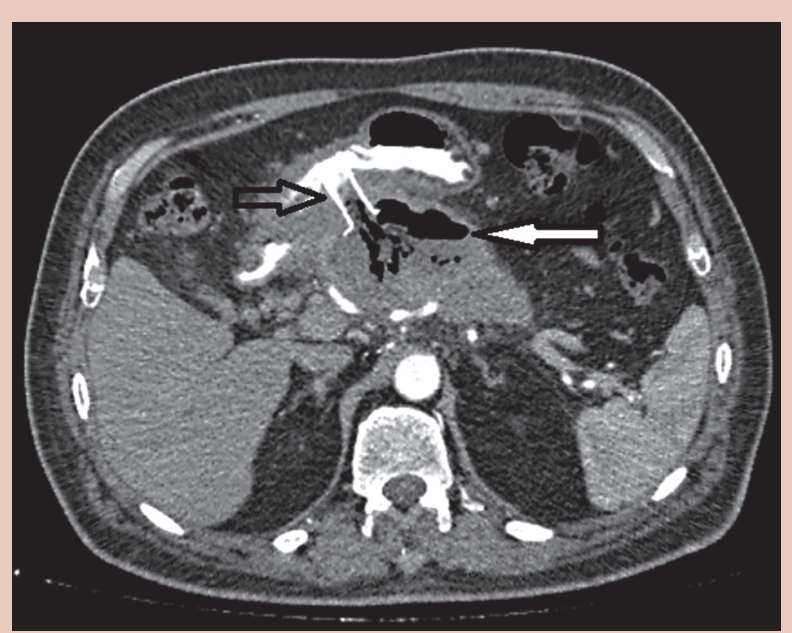

Resim 2. WON içine uzanan stent (siyak ok), kist içinde kalan debrisler (beyaz ok).

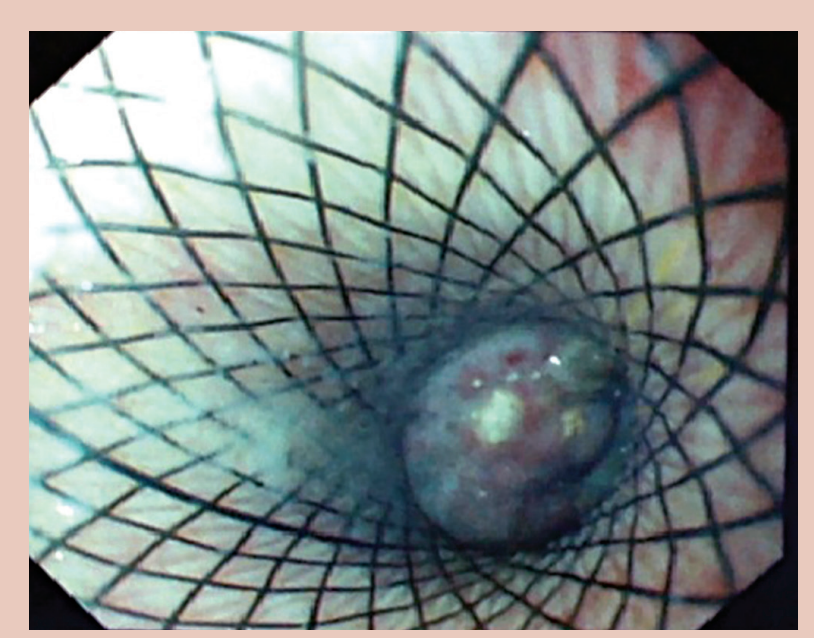

Resim 3. Metal stentin içinden endoskopik görünüm.

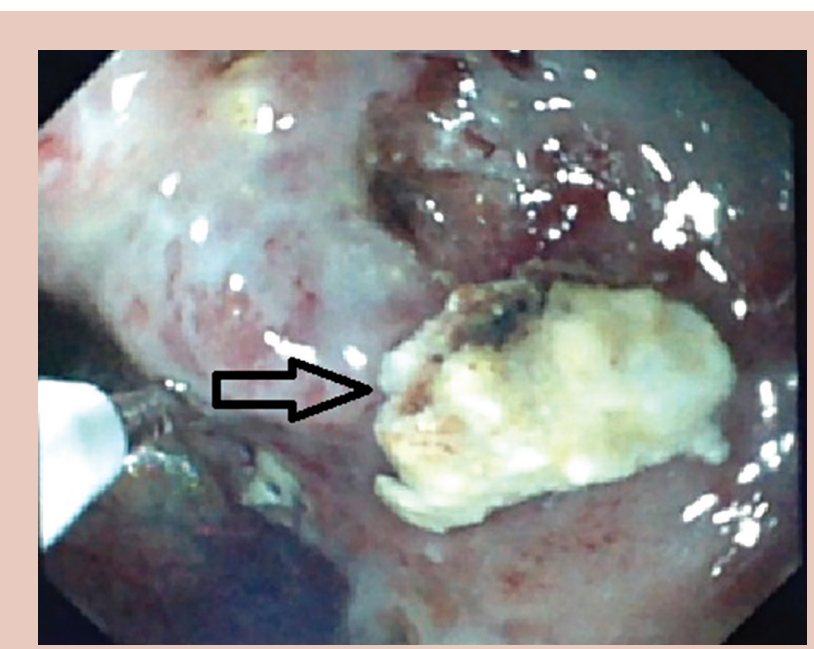

Resim 4. WON kavitesinin serum fizyolojik ile irrigasyonu ve arta kalan nekrotik debrisler (siyak ok).

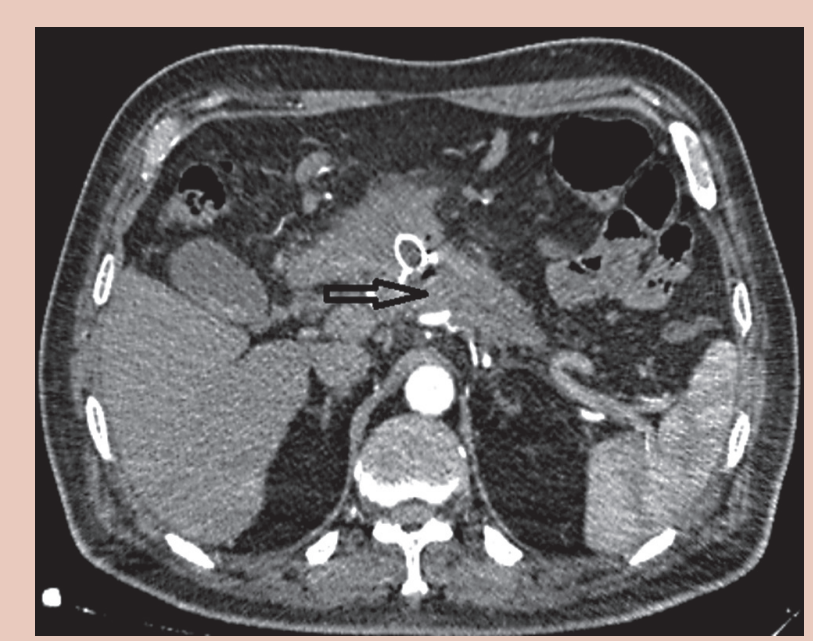

Resim 5. Endoskopik tedavi sonrası WON'un rezole olmuş hali.

te olarak veya semptomatik hale gelerek bu hastaların morbidite ve mortalitesinde artışa neden olurlar.

Psödokistlerden farklı olarak WON'u tanımak uygun tedavi için gereklidir. Endoskopik ultrasonografi, BT ve manyetik resonans görüntüleme (MRG) WON tanısında kullanılan görüntüleme yöntemleridir. BT ve MRG her iki lezyonu ayırmada faydalı olup BT'nin sensitivitesi MRG'ye kıyasla düşüktür (5). BT uygulanan hastalarda bazı radyolojik kriterler de WON'u psödokistlerden ayırmada kullanılabilir. Septasyonlar, kist içi debrisleri, kalın kist duvarı daha çok WON lehineyken pankreatik kanal dilatasyonunun $4 \mathrm{~mm}$ ve üzeri olması ise psödokist lehinedir (6). Klinik olarak akut pankreatit geçiren ve nekrozun erken tanındığı hastalarda ilerleyen haftalarda gelişen pankreatik kistler WON'u akla getirir. 
Enfekte olan ve/veya semptomatik hale gelen WON tedavi edilmelidir. Literatürde WON için bildirilen tedavi yöntemleri endoskopik nekrozektomi, perkütan drenaj, laparaskopik drenaj ve cerrahi nekrozektomidir. Perkütan drenaj siklıkla başarısız olur; nedeni WON içindeki solid komponentin perkütan yolla yetersiz temizlenmesidir. Endoskopik nekrozektomi son yıllarda giderek artan sıklıkta başvurulan bir tedavi yöntemidir. WON'un mide ve/veya duodenuma komşu olması veya bu organlara bası yapması endoskopik nekrozektomi için ilk şarttır. Endoskopik nekrozektomi için ikinci şart ise WON'un 4 haftadan uzun süredir var olmasıdır. Bu lezyonlara 4 haftadan daha erken dönemde yapilan endoskopik girişimlerin mortalitede artışla beraber olduğu literatürde bildirilmektedir (7). Her iki lezyon için uygulanılan endoskopik tedavi metodları farklılık gösterebilir. Psödokistler için yapilan transmural drenajlar siklıkla bir seansta kist sıvısını boşaltmak için yeterlidir. WON için ise sıklıkla birden fazla debritman seansı gerekir (8). Transmural drenaj her iki kistik lezyonda başarı ile uygulanırken transpapiller drenaj WON için çok uygun değildir ve psödokisti olan hastalarda daha sık başvurulan bir drenaj yöntemidir. WON tedavisinde endoskopik nekrozektomi temel hedeftir (9). Kist içi nekrotik debrisler snare ve basket gibi endoskopik cihazlar veya nazokistik drenaj ile sürekli irrigasyon yoluyla temizlenmektedir. Yine psödokistlerden farklı olarak WON tedavisinde mide lümeni ve WON kavitesi arasında oluşturulan fistül traktının daha büyük çaplı stentler yardımıyla açık tutulması gerekir.

Sonuç olarak enfekte olan ve/veya semptomatik hale gelmiş WON mutlaka tedavi edilmelidir. Mide veya duodenuma bası yapan veya yakın komşulukta olan lezyonlarda ilk tedavi seçeneği endoskopik kist drenajı ve endoskopik nekrozektomi olmalıdır. Endoskopik tedavinin WON için başarı oranı \%70-80, komplikasyon oranı \%36 ve mortalite oranı \%6 olarak kabul edilir $(10,11)$. Perforasyon, enfeksiyon, kanama, hava embolisi ve stent migrasyonu WON endoskopik tedavisi sonrası görülebilen ve ciddi seyredebilen komplikasyonlardır. Endoskopist, tedavi esnasında oluşabilecek bu komplikasyonların farkında olmalıdır.

\section{KAYNAKLAR}

1. Banks PA, Bollen TL, Dervenis C, et al; Acute Pancreatitis Classification Working Group. Classification of acute pancreatitis - 2012: revision of the Atlanta classification and definitions by international consensus. Gut 2013;62:102-11

2. da Costa DW, Boerma D, van Santvoort HC, et al. Staged multidisciplinary step-up management for necrotizing pancreatitis. Br J Surg 2014;101:65-79

3. Isayama H, Nakai Y, Rerknimitr R, et al. Asian consensus statement on endoscopic management of walled-off necrosis Part 1: Epidemiology, diagnosis, and treatment. J Gastroenterol Hepatol 2016;31:1546-54.

4. Adler DG, Siddiqui AA. What's in a name? Pancreatic pseudocysts, walled-off necrosis, and pancreatic fluid collections. Endosc Ultrasound 2016;5:215-7.

5. Morgan DE, Baron TH, Smith JK, et al. Pancreatic fluid collections prior to intervention: evaluation with MR imaging compared with CT and US. Radiology 1997;203:773-8.

6. Takahashi N, Papachristou GI, Schmit GD. CT findings of walled-off pancreatic necrosis (WOPN): differentiation from pseudocyst and prediction of outcome after endoscopic Therapy. Eur Radiol 2008;18:2522-9.

7. van Santvoort HC, Bakker OJ, Bollen TL, et al; Dutch Pancreatitis Study Group. A conservative and minimally invasive approach to necrotizing pancreatitis improves outcome. Gastroenterology 2011;141:1254-63.

8. Voermans RP, Besselink MG, Fockens P. Endoscopic management of walled-off pancreatic necrosis. J Hepatobiliary Pancreat Sci 2015;22:206.

9. ASGE Standards of Practice Committee, Muthusamy VR, Chandrasekhara $\mathrm{V}$, Acosta RD, et al. The role of endoscopy in the diagnosis and treatment of inflammatory pancreatic fluid collections. Gastrointest Endosc 2016;83:481-8

10. Bang JY, Wilcox CM, Trevino J, et al. Factors impacting treatment outcomes in the endoscopic management of walled-off pancreatic necrosis. J Gastroenterol Hepatol 2013;28:1725-32.

11. van Brunschot S, Fockens P, Bakker OJ, et al. Endoscopic transluminal necrosectomy in necrotising pancreatitis: a systematic review. Surg Endosc 2014;28:1425-38. 